\title{
Relationship between myometrial thickness and latency interval of pregnancy after preterm premature rupture of membranes
}

\author{
Wael S. Nossair* \\ Department of Obstetrics and Gynecology, Zagazig University, Zagazig, Egypt
}

Received: 11 June 2021

Accepted: 26 June 2021

*Correspondence:

Dr. Wael S. Nossair,

E-mail:wsnossair@gmail.com

Copyright: $\odot$ the author(s), publisher and licensee Medip Academy. This is an open-access article distributed under the terms of the Creative Commons Attribution Non-Commercial License, which permits unrestricted non-commercial use, distribution, and reproduction in any medium, provided the original work is properly cited.

\begin{abstract}
Background: Preterm premature rupture of membranes (PPROM) increases the risk of prematurity and leads to a number of other perinatal and neonatal complications. Prolonged latency interval increases probability of complications in mothers with PPROM. The aim of this study was to assess the relationship between the myometrial thickness and the length of latency interval after PPROM.

Methods: This study included 62 pregnant women admitted due to spontaneous PPROM from 26 to 37 weeks gestational age. All selected cases were subjected to full medical history, full clinical examination, laboratory investigations, and ultrasound evaluation with measurement of myometrium thickness at lower uterine segment and uterine fundus, measurement of amniotic fluid index.

Results: A total $32(51.7 \%)$ of our patients had latency interval $<1$ week while the rest of patients had latency interval $\geq 1$ week with mean latency interval value was $5.45 \pm 2.4$ days. Sonographic evaluation of the myometrial thickness showed that the mean thickness at lower uterine segment was $6.6 \pm 1.26 \mathrm{~mm}$ and at fundus was $6.1 \pm 1.28 \mathrm{~mm}$. we found that at cut off point $\geq 6.9 \mathrm{~mm}$ lower uterine segment myometrial thickness had $87.5 \%$ sensitivity and $93.3 \%$ specificity in prediction of latency interval $\geq 1$ week, while at cut off point $\geq 6.4 \mathrm{~mm}$ uterine fundus myometrial thickness had $81.3 \%$ sensitivity and $63.3 \%$ specificity in prediction of latency interval more than 1 week.

Conclusions: Sonographic evaluation of myometrial thickness appears to be helpful in prediction of latency interval in PPROM.
\end{abstract}

Keywords: Myometrial thickness, PPROM, Rupture of membranes, Ultrasound

\section{INTRODUCTION}

Rupture of the fetal membranes before the onset of labor before 37 weeks' gestation is referred to as PPROM. ${ }^{1}$ PPROM complicates approximately 3 percent of pregnancies and leads to one third of preterm births. It increases the risk of prematurity and leads to a number of other perinatal and neonatal complications, including a 1 to 2 percent risk of fetal death. ${ }^{2}$ Numerous risk factors are associated with PPROM. Patients at high risk for PPROM include those who have lower socioeconomic status, are smokers, have a history of sexually transmitted infections, have had a previous preterm delivery, have vaginal bleeding, or have uterine distension as well as patients who underwent cerclage and amniocentesis. ${ }^{3}$ There appear to be no single etiology of PPROM. Choriodecidual infection or inflammation may cause preterm PROM. A decrease in the collagen content of the membranes has been suggested to predispose patients to PPROM. It is likely that multiple factors predispose certain patients to PPROM. ${ }^{4}$

One of the most common complications of PPROM is early delivery. The latency interval, which is the time from membrane rupture until delivery, generally is inversely proportional to the gestational age at which PPROM occurs. ${ }^{5}$ One large study of patients at term revealed that 95 percent of patients delivered approximately within one day of membrane rupture, whereas an analysis of studies 
evaluating patients with PPROM between 16-and 26weeks' gestation determined that $57 \%$ of patients delivered within one week, and $22 \%$ had a latent period of 4 weeks.

Although prolonged latency interval increases the probability of complications in mothers with PPROM, the basic aim of expectant management in such cases is to prolong latency period because of the close association between perinatal outcomes and gestational age. ${ }^{6,7}$ Clinical practitioners face complex decisions in the management of latency period with corticosteroids, tocolytic medicines, stronger antibiotics and innovative approaches based on different experiments including amniocentesis, medical ultrasound, and biophysical experiment.

A relation between uterine myometrium thickness and latency interval has been observed in many studies, and according to this observation, sonographic calculation of uterine myometrium thickness is a simple and nonaggressive method for predicting the length of latency period. ${ }^{8}$ The aim of this study is to assess the relationship between the myometrial thickness and the length of latency period after PPROM.

\section{METHODS}

This study was a prospective cohort study composed of 62 pregnant women who were admitted at obstetrics and gynecology department Zagazig University Hospital during the period between March 2019 and January 2021 and they were enrolled in the study after fulfilling the study criteria. Ethical approval from the ethics committee of the faculty of medicine was obtained before starting the study. A written informed consent was signed by all participants before enrollment in the study.

The study included 62 patients with spontaneous PPROM from 26 to 37 weeks gestational age. The exclusion criteria were: a) women who had IUFD, fetal anomalies, nonreassuring fetal status, b) women in labor, c) women with uterine anomalies, twin pregnancy, placental abruption and chorioamnionitis, d) fetal indication of preterm labor, e) maternal indications of preterm labor and e) women who had cerclage operation.

Full history was taken from all women including personal, past history, obstetrical history for number of previous pregnancies and history of PPROM and history of present pregnancy with special emphasis for giving history of gush of clear watery fluid from vagina. PPROM was confirmed by sterile speculum (Cusco's speculum) examination to reveal amniotic fluid leak through the cervical OS and determination of amniotic fluid index by ultrasound. Fetal assessment included sonographic estimation of fetal weight obtained, fetal biometric information and biophysical profile.

Using an ultrasonographic machine with a curvilinear probe with a $3.5-\mathrm{MHz}$ an ultrasound evaluation was done at the $1^{\text {st }}$ visit within 12 hours of PPROM for assessment of gestational age, fetal wellbeing and uterine and placental position. Myometrium was detected by abdominal probe as homogenous layer between the serosa and the decidua and were measured at two sites: lower uterine segment (LUS) (approximately $2 \mathrm{~cm}$ above the reflection of urinary bladder) and uterine fundus (it was measured by keeping the scan probe above the uterine fundus). We followed the following technique: women were placed in supine position and slightly tilted to the left, then the uterus was centralized in the midline. The transabdominal sonographic examination was carried out with the bladder full to allow good visualization of the lower uterine segment and the LUS thickness was measured at two $\mathrm{cm}$ above the internal OS. the image field was magnified before taking the measurement which was obtained between uterine contractions and by the same observer and at least two measurements were obtained from the uterine wall and the average value was calculated.

Women with confirmed diagnosis of PPROM were monitored for evidence of chorioamnionitis. In the absence of signs or symptoms of chorioamnionitis and/or abnormalities of fetal heart rate, PPROM was managed expectantly after admission in the ward and were given the expectant management according to the following protocol: a) bed rest, b) maternal and fetal monitoring, c) antibiotics; unictam 375 mg every 8 hours for 10 days, d) corticosteroid; intramuscular dexamethazone $12 \mathrm{mg}$ every 12 hours for two doses after ruling out any contraindication for its administration, e) total leukocytic count (TLC) and C-reactive protein (CRP) twice weekly, f) biophysical profile (BPP) and/or cardiotocography (CTG) twice weekly for assessment of fetal well-being and/or uterine contractions for exclusion of developing labor.

The data recorded included time to delivery in weeks, mode of delivery, maternal and fetal complications and neonatal outcome.

\section{RESULTS}

Regarding the basic characteristics of the studied group; the mean maternal age of participating women in this study was $28.95 \pm 1.9$ years ranging between 25 and 33 years old, mean gestational age $31.95 \pm 2.2$ weeks ranging between 28 and 35 weeks. The mean parity value was $1.05 \pm 0.68$ ranging between 0 and 2 . The mean value of the AFI was $7.33 \pm 1.9$ ranging from 3.9 to $10 \mathrm{~cm}, 33(52.3 \%)$ women had an AFI $<5$ while $29(47.7 \%)$ women had an AFI $>5$.

The mean value of the myometrial thickness at the upper uterine segment was $6.1 \pm 1.28 \mathrm{~mm}$ ranging between 4 and $8 \mathrm{~mm}$ while the mean value of myometrial thickness at the lower uterine segment was $6.6 \pm 1.26 \mathrm{~mm}$ ranging between 4.5 and $8.4 \mathrm{~mm}$. The mean value of the latency interval was $5.45 \pm 2.4$ ranging from 1 to 8 days with $32(51.7 \%)$ women had a latency interval less than one week while 30 $(48.3 \%)$ women had a latency interval more than 1 week.

As shown in Table 1, the latency interval was significantly correlated to AFI ( $\mathrm{r}=0.264$ and $\mathrm{p}=0.038)$, to myometrial 
thickness at the upper uterine segment $(r=0.330$ and $\mathrm{p}<0.001)$ and to myometrial thickness at the lower uterine segment $(r=0.402$ and $\mathrm{p}=0.001)$.

Table 1: Correlation between latency interval and amniotic fluid index and myometrial thickness at upper and lower uterine segment.

\begin{tabular}{|lll|}
\hline Latency interval & R value & P value \\
\hline Amniotic fluid index & 0.264 & 0.038 \\
\hline $\begin{array}{l}\text { Myometrial thickness at } \\
\text { upper uterine segment (mm) }\end{array}$ & 0.330 & $<0.001$ \\
\hline $\begin{array}{l}\text { Myometrial thickness at } \\
\text { lower uterine segment (mm) }\end{array}$ & 0.402 & 0.001 \\
\hline
\end{tabular}

Myometrial thickness in the lower uterine segment at cut off point $\geq 6.9 \mathrm{~mm}$ had $87.5 \%$ sensitivity and $93.3 \%$ specificity in prediction of latency interval more than one week, while at cut off point $\geq 6.4 \mathrm{~mm}$ uterine fundus myometrial thickness had $81.3 \%$ sensitivity and $63.3 \%$ specificity in prediction of latency interval more than 1 week (Table 2). Figure 1 shows receiver operating characteristic (ROC) curve with sensitivity and specificity for endometrial thickness to predict latency interval.

Table 2: Sensitivity and specificity of myometrial thickness at the upper and the lower uterine segment in prediction of latency interval more than 1 week.

\begin{tabular}{|llll|}
\hline Variable & $\begin{array}{l}\text { Cut off } \\
\text { point }\end{array}$ & $\begin{array}{l}\text { Sensitivity } \\
(\%)\end{array}$ & $\begin{array}{l}\text { Specificity } \\
(\%)\end{array}$ \\
\hline $\begin{array}{l}\text { Myometrial } \\
\text { thickness at } \\
\text { upper uterine }\end{array}$ & $>6.4$ & 81.3 & 63.3 \\
segment (mm) & & 87.5 & 93.3 \\
$\begin{array}{l}\text { Myometrial } \\
\text { thickness at } \\
\text { lower uterine } \\
\text { segment }(\mathbf{m m})\end{array}$ & $>6.9$ & 8.3 & \\
\hline
\end{tabular}

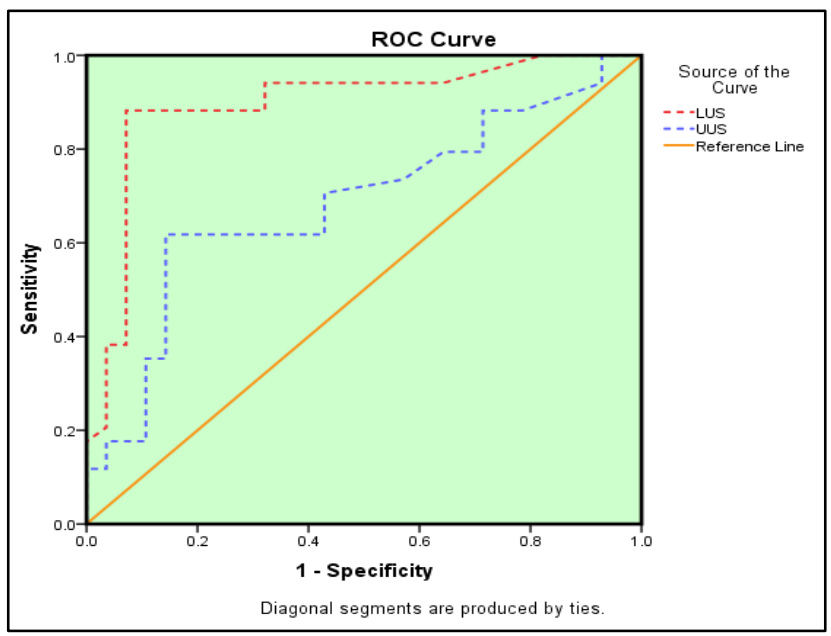

Figure 1: Receiver operating characteristic (ROC) curve represents the sensitivity and specificity for endometrial thickness to predict latency interval.

\section{DISCUSSION}

PPROM is a common and very challenging obstetric problems that needs careful management during the latency interval which is the time from PPROM to onset of labor. ${ }^{9}$ PPROM is associated with preterm delivery which is the leading cause of numerous complications especially perinatal morbidity and mortality. In the absence of symptoms and signs of infection, the management is usually expectant because of the assumption that even a minor delay in the interval to delivery will be beneficial to the fetus. ${ }^{10}$ On the other hand, prolonged latency interval increases probability of complications in mothers with PPROM. ${ }^{9}$

A relation between the uterine myometrial thickness and latency interval has been observed in previous studies. ${ }^{11}$ The aim of this study was to assess the relationship between the myometrial thickness and the length of latency period after PPROM. In order to achieve that aim, 62 pregnant women with spontaneous PPROM from 26 to 37 weeks gestational age were enrolled in this study.

Regarding the latency interval, the mean value in the present study was $5.45 \pm 2.4$ days ranging from 1 to 8 days and $32(51.7 \%)$ of the patients had a latency interval less than one week versus $30(48.3 \%)$ patients had a latency interval more than one week. These results were comparable to previous studies. Gupta et al reported that the mean latency interval in their study was $97.97 \pm 153.78$ hours (4.08 \pm 6.4 days), Buhimschi et al reported in their study done in Yale University, USA that the median latency interval was of 4 days (96 hours). ${ }^{11,12}$ Also, a study done by Singhal et al in India shows a similar mean latency period of $4.84 \pm 6.55$ days. ${ }^{13}$

Sonographic evaluation of the myometrial wall was done in the present study and the myometrial thickness was measured at lower uterine segment with a mean value of $6.6 \pm 1.26 \mathrm{~mm}$ and at upper uterine segment with a mean value of $6.1 \pm 1.28 \mathrm{~mm}$. Gupta et al reported that the average myometrial thickness in their cases was 5.34 \pm 2.28 $\mathrm{mm}$ at lower uterine segment and $9.22 \pm 3.3 \mathrm{~mm}$ at uterine fundus. ${ }^{11}$ While in the study done by Atarjavdan et al the mean myometrial thickness at lower uterine segment and at uterine fundus was $8.1 \pm 4.25$ and $8.2 \pm 3.44$ respectively. ${ }^{14}$ In the study done by Kalantari et al, the mean myometrial thickness at lower uterine segment was $8.2 \pm 2.7$ and at fundal level was $7.9 \pm 2.4 .^{15}$

In this study, the latency interval was significantly associated with AFI $(p=0.043)$, our results showed that most cases with AFI $<5$ were associated with latency interval <one week. Further statistical analysis was done to study the correlation between AFI and latency interval and showed that there was a significant positive direct correlation between both variables $(r=0.264$ and $p=0.038)$ indicating that higher AFI is associated with longer latency interval. In agreement with this result, Gupta et al reported that the relation between AFI and latency interval appears 
significant in their study implicating that PPROM cases with AFI more than $5(n=25$, mean latency interval=117.4 hours) continued pregnancy for a longer time compared to their counterparts with AFI less than $5(n=25$, mean latency interval=78.54 hours) and found a direct correlation between AFI and latency interval. ${ }^{11}$ In contrast, 2 previous studies reported that no significant difference between patients with $\mathrm{AFI}<5$ and those $\geq 5 \mathrm{~cm}$ regarding the latency interval. ${ }^{13,16}$ this was also reported by Atarjavdan et al who found no significant correlation between latency interval and AF. ${ }^{14}$

The main subject of the study was to evaluate the correlation between the myometrial thickness and the latency interval in PPROM patients and our results showed a strong direct correlation between the latency interval and myometrial thickness at lower uterine segment $(\mathrm{r}=0.330$ and $\mathrm{p}<0.001)$ and uterine fundus $(\mathrm{r}=0.402$ and 0.001$)$ in those patients indicating that thicker myometrium is associated with longer latency interval. Thick myometrium in non-laboring patients with PPROM was shown to be associated with longer latency interval. ${ }^{12}$ Our result is in line with Atarjavdan et al who reported a positive correlation between latency interval and fundal myometrial thickness $(r=0.34, p=0.02)$, and LUS $(r=0.74$, $\mathrm{p}=0.001) .{ }^{14}$

The same correlation was previously reported. Gupta et al reported that they found a positive correlation between lower uterine segment thickness and latency interval with $\mathrm{p}=0.000$. However, they didn't found no such relation between latency interval and fundal myometrial thickness with $\mathrm{p}=0.519 .{ }^{11}$ Naleini et al reported in their study on 34 pregnant women with PPROM, that a significant positive relation between latency interval with myometrial thickness in Fundal $(\mathrm{p}=0.9, \mathrm{r}=0.021)$ and lower segment $(\mathrm{p}=0.9, \mathrm{r}=0.021) .{ }^{17}$ In contrast, Kalantari et al found no relationship between the mean myometrial thickness at the lower segment or the fundus. ${ }^{10}$ This was also reported by Hamdi et al who found no significant relation between myometrial thickness and latency period. ${ }^{16}$

In this study the myometrial thickness was evaluated as a predictors of latency interval more than one week in pregnant women with PPROM and we found $87.5 \%$ sensitivity and $93.3 \%$ specificity at cut off point $\geq 6.9 \mathrm{~mm}$ myometrial thickness at the lower segment, while sensitivity and specificity were $81.3 \%$ and $63.3 \%$ respectively for myometrial thickness at the fundus at cut off point $\geq 6.4 \mathrm{~mm}$. In the study done by Atarjavdan et al they reported that a fundal thickness of $6.9 \mathrm{~mm}$ was $79 \%$ sensitive and $39 \%$ specific for the identification of women whose latency interval was 8 days, while Buhimschi et al showed that a fundal thickness less than $12.1 \mathrm{~mm}$ is $93.7 \%$ sensitive and $63.6 \%$ specific for the identification of women whose latency interval was 5 days and they concluded that a thick myometrium in non-laboring patients with PPROM is associated with longer latency interval. ${ }^{12,14}$

\section{CONCLUSION}

Sonographic evaluation of myometrial thickness appears to be helpful in prediction of latency interval in patients with PPROM.

\section{Funding: No funding sources}

Conflict of interest: None declared

Ethical approval: The study was approved by the Institutional Ethics Committee

\section{REFERENCES}

1. Caughey AB, Robinson JN, Norwitz ER. Contemporary Diagnosis and Management of Preterm Premature Rupture of Membranes. Rev Obstet Gynecol. 2018;1(1):11-22.

2. Aguilar HN, Mitchell S, Knoll AH, Yuan X. Physiological pathways and molecular mechanisms regulating uterine contractility. Human Reproduct Update. 2020;16(6):725-44.

3. Aziz N, Cheng YW, Caughey AB. Neonatal outcomes in the setting of preterm premature rupture of membranes complicated by chorioamnionitis. J Matern Fetal Neonatal Med. 2019;22:780-84.

4. Bergelin I, Valentin L. Patterns of normal change in cervical length and width during pregnancy in nulliparous women: a prospective, longitudinal ultrasound study. Ultrasound Obstet Gynecol. 2001;18:217-22.

5. Andersen HF, Nugent CE, Wanty DS, Hayashi RH. Prediction of risk of preterm delivery by ultrasonographic measurement of cervical length. Am J Obstet Gynecol. 2010;163:859-67.

6. Blanks AM, Zhao Z, Shmygol A, Bru-Mercier G, Astle $S$, Thornton S. Characterization of the molecular and electrophysiological properties of the T-type calcium channel in human myometrium. J Physiol. 2017;581(3):915-26.

7. Bergeron M, Mostaghei N, Khoshnud M. Correlation between myometrial thickness and latency interval in pattern premature rupture of membranes. Am J Obstet Gynecol. 2016;70:405-9.

8. Atarjavdan L, Khazaeipour Z, Shahbazi F. Correlation of myometrial thickness and the latency interval of women with preterm premature rupture of the membranes. Arch Gynecol Obstet. 2017;284(6):133943.

9. Naleini F, Farshchian N, Salehi MG. Studying Relationship of Myometrial Thickness Calculation with Medical Ultrasound And Latent Period Of Pregnant Women. Indian J Fundamental App Life Sci. 2016;6(1):115-22.

10. Kalantari M, Mostaghel N, KhoshnoodShariati M. Correlation between Myometrial Thickness and the Latency Interval in Preterm Premature Rupture of Membranes. Iran J Radiol. 2019;7(4):215-9.

11. Gupta R, Nagarsenkar A. Using Sonographically Estimated Myometrial Thickness in Prediction of Latency Interval in Cases of Preterm Premature 
Rupture of Membranes. J Obstetr Gynecol India. 2016;66(6):431-5.

12. Buhimschi CS, Buhimschi IA, Norwitz ER. Sonographic myometrial thickness predicts the latency interval of women with preterm premature rupture of the membranes and oligohydramnios. Am J Obstet Gynecol. 2020;193:762-70.

13. Singhal S, Puri M, Gami N. An analysis of factors affecting the duration of latency period and its impact on neonatal outcome in patients with PPROM. Int $\mathbf{J}$ Infertility Fetal Med. 2018;3:87-91.

14. Atarjavdan L, Khazaeipour Z, Shahbazi F. Correlation of myometrial thickness and the latency interval of women with preterm premature rupture of the membranes. Arch Gynecol Obstet. 2019;284(6):133943 .

15. Kalantari M. Outlines of Chordate Development. New Your: Henry Holt and Company. 2013;471.
16. Hamdi K, Bastani P, Saheb-Madarek EO. Prediction of Latency Interval in Preterm Premature Rupture of Membranes using Sonographic Myometrial Thickness. Pakistan J Biologl Sci. 2020;17:841-6.

17. Naleini JC, Doret M. Complications and monitoring of the latency period after a preterm premature rupture of the fetal membranes: Literature review. J Gynecol Obstet Biol Reprod. 2018;37:568-78.

Cite this article as: Nossair WS. Relationship between myometrial thickness and latency interval of pregnancy after preterm premature rupture of membranes. Int J Reprod Contracept Obstet Gynecol 2021;10:2932-6. 